This is an Open Access article, distributed under the terms of the Creative Commons AttributionNonCommercial-NoDerivatives licence (http://creativecommons.org/licenses/by-nc-nd/4.0/), which permits non-commercial re-use, distribution, and reproduction in any medium, provided the original work is unaltered and is properly cited. The written permission of Cambridge University Press must be obtained for commercial reuse or in order to create a derivative work.

\title{
Inference to the Best Explanation (IBE) and Archaeology: Old Tool, New Model
}

\author{
Danilo Marco Campanaro \\ Department of Archaeology and Ancient History, Lund University, Sweden
}

The last decades have seen a renewed interest in the study of argumentation in archaeology, particularly in response to the overproduction of weak and unreliable interpretations and explanations. Concurrently, recent appeals for scientific transparency and efficiency in the management of archaeological information in digital form have stressed the necessity of explicitly showing the processes followed. A growing body of literature has identified inference to the best explanation (IBE) as the most adequate way of interpreting archaeological data, although it has quietly existed for over a century. Despite this, the investigation of $I B E$-based models for recording archaeological reasoning remains a largely under-researched topic. The author concludes with a novel IBE-based model for recording archaeological argumentation.

Keywords: inference to the best explanation (IBE), archaeological reasoning, digital archaeology, 3D reconstruction, IBE-based pipeline

\section{INTRODUCTION}

Inference to the best explanation (IBE) has been the theme of a lively debate among philosophers who have often found themselves divided about the validity of this pattern of reasoning (van Fraassen, 1989; Kapitan, 1992; McMullin, 1992; Lipton, 2004; Paavola, 2005). Despite a certain dependence on philosophy-led accounts, especially during the 1970s and 1980s, much ink has been spilled in archaeology on methods of investigation while few studies have addressed the specific topic of how archaeologists come to their conclusions (Gardin, 1980; Hodder, 1999). In the last few decades, however, a growing number of scholars has addressed more deeply how archaeological reasoning has structured itself (Salmon, 1982;
Hanen \& Kelley, 1989; Gardin, 2002, 2004; Wylie, 2002; Fogelin, 2007; Smith, 2015; Chapman \& Wylie, 2016; Lucas, 2018). Among them, Hanen and Kelley (1989) and Fogelin (2007) have identified IBE as an effective pattern for hypothesis selection in archaeology. Importantly, this connects with the most recent advances in bottom-up theorizing in archaeology (Reichertz, 2007; Lucas, 2015) and contemporary debate about the management of archaeological information in digital form (Dallas, 2016).

In this article, I examine how this particular type of inference has manifestly or more subtly found an application in the recent history of archaeological reasoning. In addition, a specific IBE-based 'pipeline' for recording archaeological reasoning will be defined in the light of the arguments discussed. 
An account of IBE against two other major types of inference, deduction and induction, is given here, followed by an examination of the pervasiveness of the inference to the best explanation in archaeological reasoning. Finally, an IBE-based methodology is defined, building on an assessment of recent studies and on some findings from a case study in Pompeii (in Campanaro, in prep.), to suggest how the IBE-based procedure outlined here may be used in practice.

\section{INFERENCE TO THE BEST EXPLANATION}

Inference to the best explanation, or abductive reasoning, has often been identified as one of the three major types of inference, together with deduction and induction. Despite being still a matter of controversy, with opinions ranging from 'no inference at all' (van Fraassen, 1989: 161) to 'the inference that makes science' (McMullin, 1992), many philosophers agree on defining IBE as commonly used both in everyday life and scientific reasoning. It can be useful, before analysing the connection between archaeology and IBE, to explain in greater detail what IBE is, compared to deductive and inductive patterns. First, a distinction should be made between necessary and non-necessary inferences, namely between deduction on the one hand, and induction and abductive reasoning on the other.

A textbook example of deductive reasoning is: All men are mortal / Socrates is a man / Therefore, Socrates is mortal.

The essence of deduction lies in an appropriate relation between the premises and the conclusion, namely that the last proposition, inferred from the first two premises, is necessarily true if the premises are true.

Yet, not all inferences are of this kind. Consider, for instance, the following: $A$ lives in $B /$ Most people living in $B$ are poor $I A$ is poor.
In this example, the truth of the conclusion is likely to be inferred from the premises, i.e. even if the premises are true, the conclusion could be different. A second group of non-necessary inferences can thus be introduced, comprising inductive and abductive reasoning. The main trait of this class of reasoning seems to be an inference based on statistical data.

Consider now the following example suggested by Okasha (2002: 29): The cheese in the larder has disappeared, apart from a few crumbs / Scratching noises were heard coming from the larder last night / Therefore, the cheese was eaten by a mouse. The premises do not entail the conclusion as in a deductive pattern. Here the conclusion can be inferred as the one that best explains the given set of data.

A further distinction between abductive and inductive reasoning can be suggested: although both are ampliative (their conclusions go beyond what is included in their premises), the first invokes explanation whereas the second only refers to frequencies or statistics. To clarify, '[...] in abduction there is an implicit or explicit appeal to explanatory considerations, whereas in induction there is not; in induction, there is only an appeal to observed frequencies or statistics' (Douven, 2017).

Why, then, prefer abduction or IBE over other forms of inference? It is useful here to anticipate some of the issues developed later. Given the limitations shown by the hypothetico-deductive method in archaeological research (see below), one might assume that induction must be involved in a great deal of good archaeological reasoning' (Fogelin, 2007: 606). Yet, statistical inductions, being highly dependent on previous observations (both in terms of quantity and diversity), would not adequately address particularities in the past. For example, 'when archaeologists evaluate inferences concerning the Pyramids of Giza, how many other 


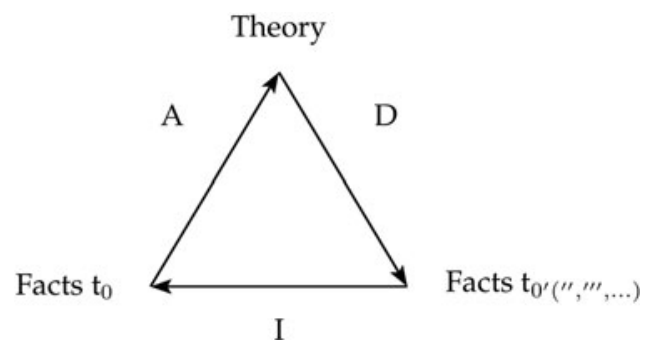

Figure 1. The dynamic interaction of abduction, deduction, and induction (after Minnameier, 2010: 241, fig.1). Copyright (C) 2010 Minnameier and the Nordic Pragmatism Network. AttributionNonCommercial 3.0 Unported (CC BYNC 3.0)

massive, awe-inspiring pyramid complexes along the Nile can they observe?' (Fogelin, 2007: 608). In this sense, the inference to the best explanation would be an advance over statistical induction since it can account for multiple lines of evidence for infrequent phenomena in archaeology. Additionally, as claimed by Weintraub (2013: 203), IBE would be an 'autonomous (indispensable) form of inference' and induction a special case of it, so that when we infer a generalization from a uniform sample, we are applying IBE standards (Weintraub, 2013: 210).

Before proceeding further, some clarification concerning the use of the terms IBE and abduction is needed. In the historical sense, Peirce (1931-1958) first coined the term 'abduction' and proposed a specific dynamic involving deduction and induction. According to Peirce 'Abduction merely suggests that something may be. Its only justification is that from its suggestion deduction can draw a prediction which can be tested by induction' (Peirce, 1931-1958, vol. 5: 171). In this formulation, the aim of abduction is to lead to a new concept or theory that explains surprising facts ( $t_{0}$ in Figure 1 ). In the 1960s, Harman proposed his own interpretation of abductive reasoning, identified by him as IBE, so that when adopting it 'one infers, from the premise that a given hypothesis would provide a "better" explanation for the evidence than would any other hypothesis, to the conclusion that the given hypothesis is true' (Harman, 1965: 89). In sum, the best explanation is also the most likely to be true, a truth relative to evidence and the current state of knowledge (Minnameier, 2010).

Interestingly, especially for archaeology, a relevant distinction between the two formulations is that Harman advocates using IBE not just in the first of the two stages of scientific enquiry (the logic of discovery and the logic of justification). Channelling Amaya (2009) and Niiniluoto (1999), it is possible to identify two forms of abductive reasoning, labelled weak and strong. In its weak form, abduction exhausts its role within the sole logic of discovery. In its strong form, abduction, identifiable with IBE, operates both in the context of discovery and in that of explanation, thus challenging the separation originally identified by Reichenbach (1983). The latter saw discovery as a mere domain of psychology and explanation as the realm of real science (Reichertz, 2007: 216). Here, I specifically refer to IBE in its strong form.

\section{IBE and Archaeological Reasoning}

In the last few decades, a renewed interest in the structure of logical reasoning has been the subject of several contributions in archaeological research (Gardin, 1980, 2002, 2004; Salmon, 1982; Hanen \& Kelley, 1989; Wylie, 2002; Fogelin, 2007; Smith, 2015; Chapman \& Wylie, 2016; Lucas, 2018). Many issues concerning archaeological argumentation and explanation have been addressed, along with the question of whether archaeology can be considered a science or not. For the latter, and for our purpose here, it will be 
sufficient to point out that, for archaeology and science alike, knowledge is responsive to evidence and claims are continuously exposed to challenge (Smith, 2015). Furthermore, as noted by Chapman and Wylie, although material traces may give rise to epistemic pessimism, they have a 'remarkable capacity to bear witness to the cultural past in ways that do often subvert our presentist convictions and expand our interpretive horizons' (Chapman \& Wylie, 2016: 33).

Some of the studies mentioned above have stressed the importance of IBE as an effective pattern in archaeological reasoning (Hanen \& Kelley, 1989; Fogelin, 2007). Among them, Fogelin has emphasized the role of IBE in archaeology as an underlying companion to the standard disciplinary practices for over a century. In order to investigate the enmeshment between IBE and archaeological reasoning, some traits of the recent history of the archaeological theorization and its connection with the philosophy of science will be retraced here (see Lucas, 2018 and Chapman \& Wylie, 2016 for an historical review of epistemological debates in archaeology).

Initially, with the popularization of 'new' or processual archaeology in the 1960s by Lewis Binford (1968), attention was drawn on epistemology and the problem of structuring effective archaeological arguments. Consequently, 'new archaeologists' agreed on adopting, as a specific formal model, a method commonly used in science to challenge universal statements and laws: the deductive-nomological pattern as defined by Hempel (1966), also known as the 'covering law'. Along with this desire for a theory that could produce generalizations about cultural process, came an interest in a more rigorous method of archaeological interpretation to justify such generalizations, the hypothetico-deductive model (Lucas, 2018). In this light, researchers were asked to look for universal laws of human behaviour, following the principle that in a deductively valid argument, the conclusion is related to the premises in such a way that if the premises are true then the conclusion cannot fail to be true as well' (Hempel, 1966: 10). This model, then already considered inappropriate by the social sciences, soon proved to be inadequate for archaeological inquiry too (Smith, 2015: 18). As Fogelin (2007: 605) notes, while it is possible for a scientist to determine the validity of deduction (if the premises are true then the conclusion is also true), no mechanism to assess the objective of the truth of the premises is available.

Once the limitations of the covering law model in archaeology were recognized, archaeologists started to find new references in the philosophy of science. While some scholars looked at the statistical nature of archaeology as an alternative method of scientific explanation (Salmon, 1982), others, building on Karl Popper's falsification theory (Peebles, 1992), maintained that hypotheses could only be rejected. Some borrowed scientific methods from biology or geology (Dunnell, 1982), while others, like Hodder, have stressed the need for an anti-positivist view that '(...) hypotheses are not tested on archaeological data and that theory and data do not confront each other within an objective science of archaeology' (Hodder, 1984: 26). Jean-Claude Gardin (1980) proposed a distinctive approach in the 1980s, termed logicism. This consists of a meta-theoretical programme aiming to scrutinize the arguments used by archaeologists in their interpretations, irrespective of the paradigm they may be associated with. Despite promising and promoting the field of archaeological databases, expert systems, and knowledge bases, this approach eventually appealed solely to logico-deductive and empirical-inductive argumentation, leaving aside archaeological arguments based on abduction and not 
recognizing the latter's centrality to archaeological research (Dallas, 2016: 323).

At the end of the 1990s, a tacit agreement on pluralism prevailed, leading to a sort of 'epistemic silence' (Hegmon, 2003: 230) and an enfeebled debate on epistemological issues in the new millennium. Lucas (2018) identifies three main streams in this period: indigenous archaeology, neo-empiricism, and evidential reasoning. The latter would include Alison Wylie's approach and proponents of IBE (Hanen \& Kelley, 1989; Fogelin, 2007). In this framework, Wylie's emphasis on 'argument' and 'logic in use' advocates 'robustness' in reasoning (Lucas, 2018: 61). This mobilizes multiple lines of evidence warranting knowledge claims 'as credible given available resources' (Chapman \& Wylie, 2016: 11). Lucas (2018), in turnwhile accepting IBE (as illustrated by Fogelin, 2007 and Hanen \& Kelley, 1989) and Chapman and Wylie's 'argument' as a means to adjudicate between different knowledge claims - is 'less ready to see it as the only way to do this' (Lucas, 2018: 63). In order to connect traditional epistemological issues to the more recent work on knowledge production, Lucas uses the function of writing and textual composition, broadly connecting with Gardin's distinction between field records, archives, and databases on the one hand, and interpretive texts on the other. Other authors propose Peirce's semiotics as an alternative to Saussurean and post-Saussurean approaches (language models applied to the study of meaning by social scientists) for understanding material culture (Preucel \& Bauer, 2001) or to engage with the non-representational (Crossland \& Bauer, 2017). Preucel and Bauer relate the logical Interpretant-i.e. the 'meaning of the Sign that is conjured by the interpreter' (Harris \& Cipolla, 2017: 116), one of three elements, the other two being the Sign itself and the Object representing the structure of a sign according to Peirce (1998: 409) to 'abductive' reasoning and 'the way we build an argument' (Preucel \& Bauer, 2001: 91), opening their model to the logic of the multiple lines of evidence envisaged by Wylie.

Fogelin (2007) notes that, to date, IBE has been practically excluded from the archaeological discourse about epistemology. Few authors have stressed how IBE patterns are commonly found in both the 'new archaeology' and earlier archaeological studies. In their seminal work, Hanen and Kelley (1989) demonstrate how the strategy at the root of two very different examples of archaeological reasoning boils down to inferring the best explanation from competing alternatives. Fogelin, building on Hanen and Kelley, proposes IBE as the underlying standard in archaeological reasoning for almost a century and bridging processual and post-processual theories. In particular, he develops a thorough analysis of different cases from the 1920s to processualism and beyond. Here, I present his interpretation of Ian Hodder's post-processual 'hermeneutics'.

In 'Interpretive Archaeology and its Role', Hodder (1991) explains how the starting point of his theory is the 'hermeneutic circle', a dialectical relation between the parts and the whole. The hermeneutic process, as Hodder defines it, aims to identify different contexts and bring them into a more coherent explanation: a circle where different contexts-e.g. the archaeologists' context, including their preconceptions and social values, and the context of the people who created the archaeological material-overlap in order to create explanations dynamically. Nevertheless, hermeneutics would implicitly rely on IBE to evaluate hypotheses, in that, as Hodder himself explains, successful hermeneutics work in terms of how much of the data is accounted for by our hypothesis in comparison to other hypotheses' (Hodder, 
1991: 8). In addition, Hodder maintains a certain 'guarded' objectivity towards the material remains, to counter the sense of disabling relativism derived from early post-processual claims of equivalence between different readings of the past (Halsall, 1997). Hodder (1992: 175) consequently dismisses the hermeneutic circle as vicious, in favour of a spiral where the interpretative process is always moving forward, a point previously made by Shanks and Tilley (1987; Lucas, 2018: 48). In this perspective, the sole difference between processualism and post-processualism would apparently lie in the adoption of hermeneutics and critical theory. In turn, as noted by Fogelin (2007: 614), a common reasoning pattern, embedded in hermeneutics, as well as in the archaeological cases examined by Fogelin, can be pinpointed: the inference to the best explanation.

\section{Better Explanations in Archaeology}

Before presenting the proposed IBE-based 'pipeline' in light of the arguments set out above, the specific question of explanation or 'the fundamental question of all serious fields of scholarly enquiry: how would you know when you are wrong?' (Haber, 1999: 312) will be addressed.

Fogelin (2007: 615) remarks that explanation in archaeology has often been identified in terms of causation. In this respect, Smith (2015: 22) notes that this model started flourishing after the demise of the 'covering law' in order to 'exhibit the mechanism(s) that make the system tick' (Bunge, 2004: 182). The main shortcoming in explaining an archaeological phenomenon in terms of causation is the problem of infinite regress (why-regress), i.e. that every causal explanation demands further explanations, ad infinitum. One way of addressing this issue is to limit the range of investigation to the proximate causes, with the evident drawback of excluding possible interesting causes from the analysis. On the other hand, Lipton invokes the why-regress feature as saliently benign in that '[it] provide[s] understanding even if we have no answer to whyquestions further up the ladder' (Lipton, 2001: 45). Another solution, suggested by Flannery (1986: 517), is to address the four causes as presented by Aristotle: the material cause (out of which anything is made), the efficient cause (the source of motion), the formal cause (shape or appearance of the thing), and the final cause (that for the sake of which a thing is done). Despite its potential to clearly describe different types of cause, this method has several drawbacks. First, it does not permit establishing which explanation is better than another: as noted by Fogelin (2007: 616 ), in order to solve this issue, Flannery relies on Ernst Mayr's (1982) theories, who ultimately refers to IBE. Second, causalitybased accounts of explanation cannot be the whole story (Okasha, 2002: 52), in that explanations often deal with meaning rather than causation (e.g. finding the best meaning of a word among different other possible meanings).

What then makes an explanation a good explanation? Smith (2015: 21) advocates the adoption of an epistemological hierarchy (Figure 2) to ensure the success of archaeological arguments. In this view, a grand theory or high-level theory is only used for providing a context to middlerange theories that in turn serve the explanatory purpose, a concept first introduced by Robert Merton in the 1940s (Merton, 1949). This stance is similarly advocated by Bruce Trigger (2006: 508), who assumes that every form of inference (archaeologists' ideas about the past) put forward with different degrees of probability, may fall under the middle-range theory umbrella, which also comprises 


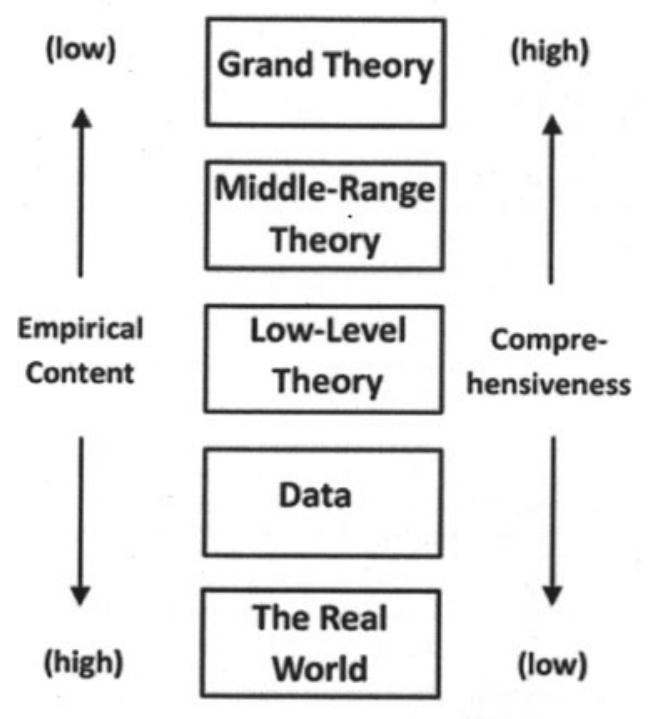

Figure 2. Epistemological bierarchy (after Smith, 2015: 22, fig. 3). Reprinted by permission of the Society for American Archaeology from The SAA Archaeological Record, 15 (4), p. 22.

Binford's personal conception of a middlerange theory. Additionally, Trigger, unlike Gardin (1980: 27), warns that an approach altogether dismissing high-level theory inevitably exposes archaeological interpretations to the prejudices of the societies or social groups to which they belong. By contrast, Hodder (1986) maintains that middle-range theory, like other naturalscience methods applied to archaeology, appears to be inadequate in that it entails cross-cultural generalizations neglectful of important aspects of the past (such as ideas, intentions, and meaning).

How can we harmonize such different levels, reconcile the social with the ground? Lucas, in his seminal article on the mobility of theory in archaeology (Lucas, 2015), remarks on the lack of attention paid to Merton's theory, which would have influenced the surge of a new wave of sociological theorizing, the
Grounded Theory (GT). In this approach, data would be used to generate theory, not to test it, much resembling middle-rangetheory in this respect. GT would favour the abandonment of the hypotheticodeductive method and foster a tendency to a reflexive approach. Eventually, GT, initially suffering from an inductivist selfmisunderstanding, would become progressively abductive in its later stage (Reichertz, 2007). This resonates with Lucas' introduction of the most recent advances in GT as possibly connected with post-positivist epistemologies, namely IBE. Lucas maintains that the whole point of a bottom-up approach, far from addressing questions of how to generate general theory from the bottom, is instead concerned with connecting multiple theories arising from the data, both in archaeology and in cognate fields (e.g. history).

What remains at stake is the issue of how to evaluate explanations in archaeology. Fogelin (2007), channelling Quine and Ullian (1978), suggests seven 'virtues': generality (a good explanation should be employed for a wide array of phenomena); modesty (the explanation should not overreach); refutability (explanations should be refutable); conservatism (explanations should not primarily aim to overthrow well-established principles); simplicity (using Occam's razor, explanations should not be more complicated than necessary); empirical breadth (a good explanation should address several empirical phenomena and not be contradicted by others); and multiplicity of foils (for example, why one particular thing happened and another did not), in that the more foils the better the explanation. Interestingly, Amaya (2009), addressing problems of best legal explanation, has proposed IBE as a process of coherence-maximization, with a clear link to the philosophy of science, consisting of two stages: the creation of a series of candidate 'theories of the cases' 
and the selection of the option that coheres the best. Evidently, coherence permeates the entire procedure, from the generation of the hypotheses to the selection of the best among the plausible explanations presented. From an original base of coherence, comprising evidence and some competing explanatory hypotheses, a 'contrast set' is built, which in turn includes an array of plausible alternative theories to be refined. While Amaya's (2009) proposal applies to jurisprudence and cannot be discussed here in detail, the use she makes of coherence theory has relevance for archaeology.

Coherence-maximization plays a key role in Amaya's (2009) study: it creates a constant feedback between evidence and the hypotheses, helping to narrow them down against background knowledge and to discard 'crazy ideas' ('the crime was committed by an unnatural force'; Amaya, 2009: 139). Plausible alternatives are then refined into full-blown theories through coherence-making strategies: subtraction of elements from an incoherent set; addition of elements to increase the coherence; reinterpretation as a combination of the two first strategies. Last, the best candidate is selected among a number of plausible scenarios. In this last phase, IBE is imbued with Thagard's (1978, 1989, 1992) conception of explanatory coherence. This theory, conceived in response to the long-standing question of the evaluation of competing hypotheses, is intended to account for a wide range of explanatory inferences (Amaya, 2015: 214). Thagard's explanatory coherence represents an improvement on the classic methodology of Lakatos (1970; Magnani, 2009: 83). It responds to the claim that extra-rational motivations are unavoidable (Kuhn, 1962; Feyerabend, 1975) in that scientists 'sometimes [...] too are conditioned by motivationally biasing their inferences' (Magnani, 2009: 22).
According to Thagard, coherence between propositions of a particular theory $\mathrm{P}$ and $\mathrm{Q}$ exists if there is some explanatory relation between them or more specifically if one of the following four cases is true:

1) P is part of the explanation of $Q$

2) $Q$ is part of the explanation of $P$

3) $P$ and $Q$ are together part of the explanation of some proposition $\mathrm{R}$

4) $P$ and $Q$ are analogous in the explanations they respectively give of some proposition $\mathrm{R}$ and $\mathrm{S}$.

The global coherence of an explanatory system is then assessed by means of seven principles (symmetry, explanation, analogy, data priority, contradiction, competition, and acceptance). Commonalities with Quine and Ullian's (1978) virtues can be found, for example between the important principle of explanation and the virtues of explanatory breadth and simplicity; with explanatory breadth being the most important criterion for selecting the best explanation as claimed by Thagard (1978). For the sake of this study, only the seven virtues by Quine and Ullians will be assumed as a reference framework against which the entire process of alternative generation and the consequent selection of the best explanation among several plausible options will be performed.

With reference to plausibility, and in response to van Frassen's 'argument from the bad lot' (van Fraassen, 1989: 143), namely the possibility that the best explanation may just be the best of a 'bad lot', the literature has addressed this issue at length (Lipton, 1993; Psillos, 1996; Okasha, 2000; Iranzo, 2001). It will be sufficient here to stress the key role played by background knowledge in the selection of plausible alternatives, which does not occur in a 'conceptual vacuum' (BenMenahem, 1990: 330). In addition, Amaya (2009) appeals to an idea of 
epistemic responsibility, where complying with some epistemic duties and virtues may ensure that a set of hypotheses is 'good enough'. As for the concept of epistemological duty, Feldman (2002: 383) reminds us that 'What we epistemologically ought to do, whenever we consider a proposition, is to have the attitude that is justified for us. To do so is the extent of our purely epistemological duties.'

At this juncture, we can turn to the adoption of explicit structures of argumentation to help archaeologists formulate better cases, reinforce their theoretical underpinnings, and tackle the 'sense of bewilderment [...] regarding the profusion of conflicting theories' (Gardin, 2002: 269). This also provides an indispensable tool to tackle appeals for transparency in the process of $3 \mathrm{D}$ reconstruction or effective documentation in the digital archiving of archaeological contents.

\section{The Relevance of Explanations in Archaeology}

The important point that an IBE-based logical pattern has been a constant and silent companion of archaeological reasoning over decades, still leaves out why archaeologists should consider substantiating their arguments and, most importantly, why they should make it explicit in their publications. The need to clarify the reasoning processes underlying an archaeological explanation is twofold: first, to fulfil the necessity of building solid archaeological theories by means of welldefined arguments; and second, to cope with issues of archiving and re-use, which the field of archaeological informatics is signposting as an urgent priority. In this respect, the work of Gardin (2002) is relevant. Gardin contends that complex historical phenomena, (such as the emergence of agriculture or the rise, decline, and fall of the Maya empire) are evidently intertwined by means of explanatory processes. This would equally apply to 'more modest' archaeological manifestations, so that attributing a function or space/time coordinates to a given find would be no less a way to 'explain' it. Eventually, the distinction between explanatory constructs and the products of description (excavation reports, corpora, etc.) as commonly intended could be revised, since no 'natural' descriptions exist in archaeology and every description 'bears the mark of past theories' (Gardin, 2002: 267-68). Indeed, all scientific statements may be considered explanatory; as Johnson (2010: 24) puts it, 'the driest, most descriptive text or site report is already theoretical'. Despite informing archaeological practice everywhere but with different degrees of transparency, the explanatory logics underpinning archaeological reasoning still receive scarce attention in scholarly production.

At the same time as calling for a more consistent structuring of archaeological reasoning, archaeology must consider the production and management of archaeological information in digital form. Here, I present the main issues related to archaeological informatics, in order to clarify the importance of the production of sound and explicit forms of argumentation in archaeology and the introduction of an IBE-based methodology.

The profusion of three-dimensional (3D) virtual reconstructions in the field of cultural heritage in the last decades has highlighted issues relating to the reliability, scientificity, and transparency of the processes behind those reconstructions. Initiatives such as the London Charter (2009; LC hereafter) and the Seville Principles (2017, SP hereafter) have urged the need to incorporate metadata (descriptions accompanying the data) and paradata (SP, 7.3), or the 'the evaluative, analytical, 
deductive, interpretative and creative decisions made in the course of computerbased visualisation' (LC, 4.6) in order to ensure the necessary scientific transparency. In response to this specific concern, scholars have stressed the importance of documenting the entire reconstructive process (Demetrescu, 2015; Demetrescu et al., 2016; Demetrescu \& Fanini, 2017), not leaving the reasoning structure behind those virtual reconstruction undocumented and 'lost to the scientific community for interrogation and future use' (Bruseker et al., 2015: 33). Demetrescu and Fanini have introduced the concept of a 'Report of Virtual Activities', a textual version of their 'Extended Matrix', that acts as sort of 'mind map' of the researcher's intuition, 'for quick sharing of the reconstruction hypothesis' (Demetrescu \& Fanini, 2017: 505). Concurrently, Bruseker et al. (2015), putting the accent on the reasoning process ('knowledge provenance') behind every hypothesis formulated by experts in computer-based visualizations, have proposed a generic documentation model linking the virtual reconstructions with their reasoning. Despite not pointing to any specific form of logical inference as a driving force for the choices behind those virtual processes, these contributions mention the possibility of self-excluding, coexisting hypotheses (Demetrescu \& Fanini, 2017: 508) or an iterative process of constraining the choices 'left available to the modeler' (Bruseker et al., 2015: 36). In this light, the process of $3 \mathrm{D}$ reconstruction may well be seen as explanatory and similarly stemming from an IBE-based chain of argumentation, three-dimensionally rendering the best from of a set of possible theories concerning the object of inquiry.

Several attempts have also recently been made to offer openly accessible catalogues of archaeological finds, monuments, and sites (Dallas, 2016: 319-20), with metadata, representing the archaeological record, assuming a paramount importance in archiving, re-use of the data, and publication. Dallas, following Gardin's idea that data publication and the publication of archaeological argument are inseparable, has stressed the relevance of the enmeshing the documentation and curation of archaeological data with their interpretation, eventually calling for the abandonment of a purely logico-deductive and empirical-inductive argumentation included in the logicist approach (Figure 3). Dallas advocates embracing IBE, in line with Grize's (2000) critique, and in tune with the centrality, recognized in archaeological practice, of this pattern of reasoning.

\section{A Proposal for an IBE IMPLEMENTATION}

Despite its contribution to the affirmation of IBE as an effective pattern of archaeological reasoning, the existing literature has not offered a specific pathway ("pipeline' hereafter) for the application of IBE to archaeological reasoning. I shall therefore investigate the model described by Gardin (2002) and scrutinize it in the light of the implementation of an IBEbased process of argumentation, with the aim of defining such a pipeline for recording and making explicit the archaeological reasoning chain, based on Gardin's logic of inference.

At the core of the logicist model is what Gardin calls schematization (Figures 3 and 4). Borrowing from Grize's theory, schematization is intended as 'models generated through a discourse in natural language' (Grize, 1974: 204) in contraposition to formalization, which appeals to the realm of mathematical models and formula. Moreover, it differentiates this discourse in natural language from text written in a linear discourse as being more concise, not 


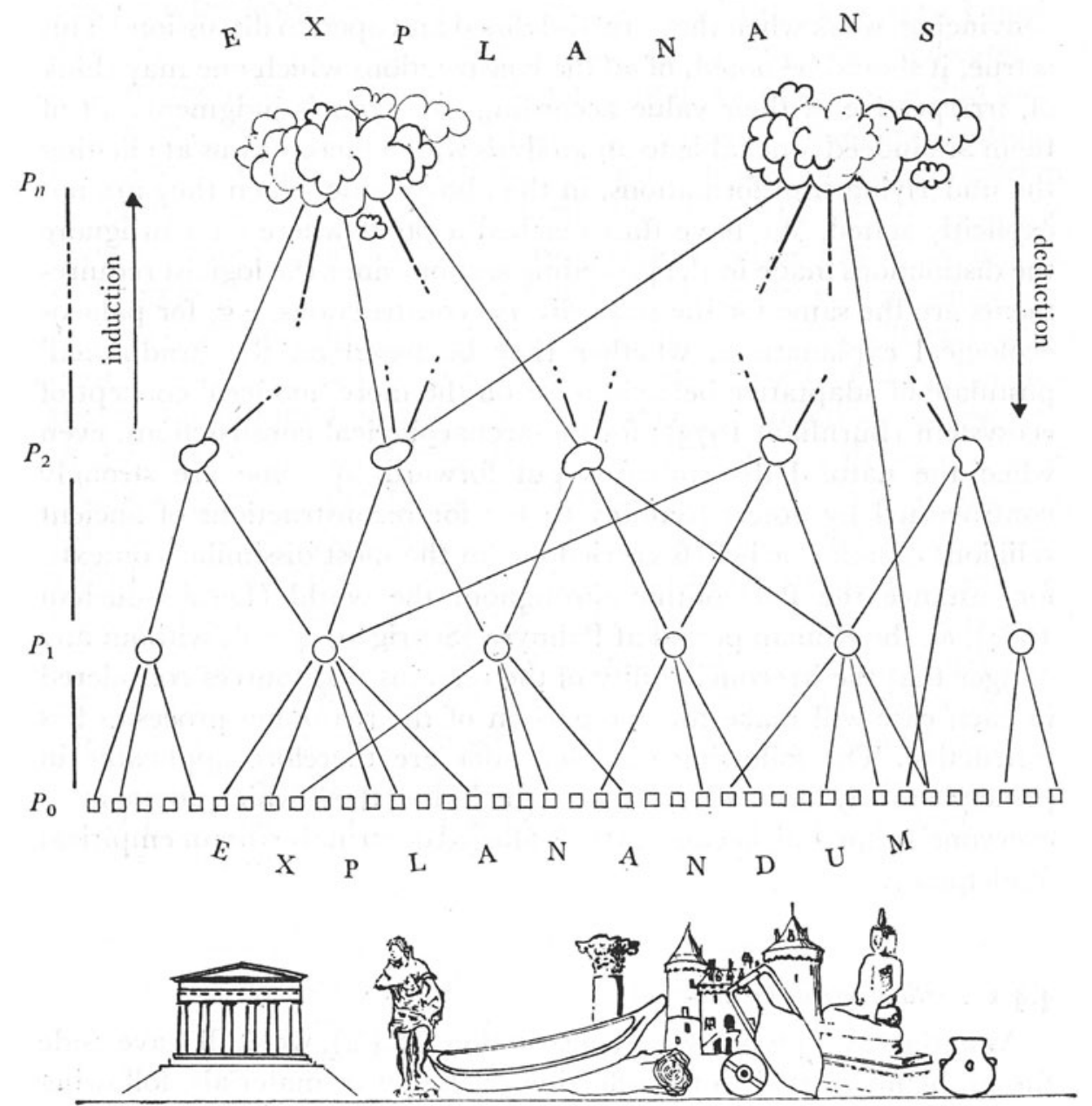

Figure 3. Gardin's model (from Gardin, 1980: 103, fig. 20). (c) Maison des Sciences de l'Homme and Cambridge University Press 1980. Reproduced with permission of Cambridge University Press through PLSclear.

retaining all the information and pointing at 'expressing the whole logical structure of the interpretative or explanatory theories developed in such texts' (Gardin, 2002: 275). The adoption of such a model stems from the necessity to cope with the crisis affecting archaeology and social science, defined by two major aspects: first, the sheer number of superseding or contrasting archaeological paradigms; and second, the overproduction of text, seen as a downside of the explosion of informatics, where more is produced than could possibly be read. Emphasizing brevity and the clear definition of the structure behind archaeological reasoning, Gardin suggests schematization as a possible remedy. An example of a workflow based on the principles of the logicist programme can be found in Marlet et al. (2019). This digital publication of the archaeological excavation of the settlement and church in Rigny (Indre-et-Loire, France) is complemented by work that maps the structure of the reasoning. 


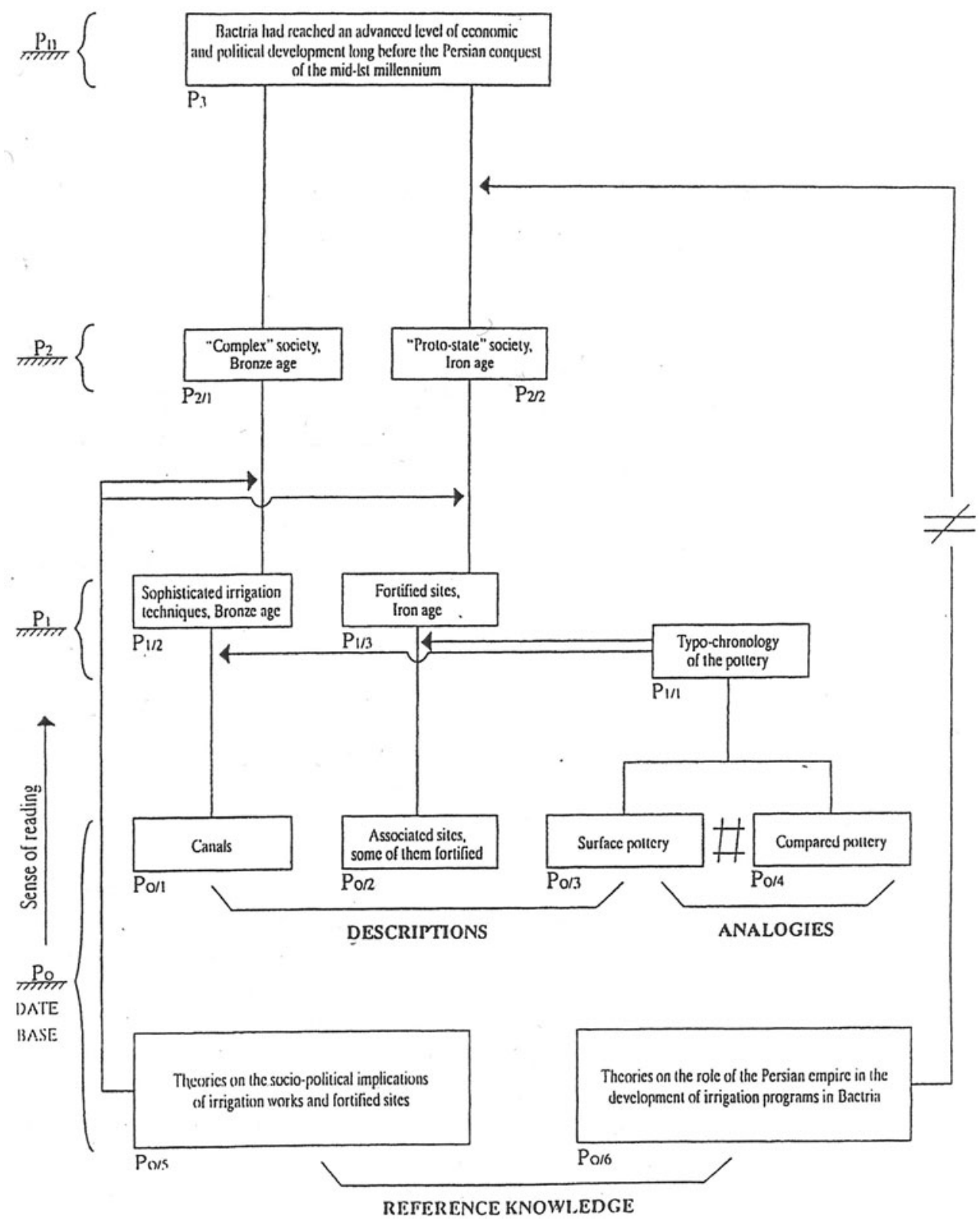

Figure 4. Example of schematization (from Gardin, 2002: 273, fig. 2). Reprinted by permission of Springer Nature.

The objective is, therefore, to bridge the three main elements of an archaeological discourse: the descriptions, their meaning (or interpretation), and the arguments connecting descriptions and meaning.
The first of the three categories comprises elements that merge with the ample concept of a database (P0 in Figure 4), including descriptions but also references to knowledge or antecedent theories used 
to underpin the inferences found in the text and the analogies used to establish correspondences between objects based on their characteristics.

The second refers to the propositions (or conclusions) that stem from the argumentation process or the starting hypotheses to be established ( $\mathrm{Pn}$ in Figure 4).

The last category includes the series of arguments that link the database to the conclusions, operations that Gardin identifies with rewrite formulas of the kind $\mathrm{p} \rightarrow \mathrm{q}$. This means that, given a set $\mathrm{Pn}$ of hypotheses or conclusions and a set of propositions P0 composing the database, it is possible to proceed inductively from a subset of $\mathrm{P} 0$, through successive inferential passages, of the type $\mathrm{P} 1 \rightarrow \mathrm{P} 2$, to the conclusions $(\mathrm{Pn})$ or in reverse order, deductively from $\mathrm{Pn}$ to P0. Interestingly, despite defining this method as irrespective of the method used, Gardin's method solely considers induction and deduction as forms of logical inference (see also Marlet et al., 2019: fig. 4).

Notably, as stated by Gardin himself, schematization tells us nothing about the nature of the arrows, being focused on the verification of the potential conversion of theories into 'IF $\mathrm{p} \rightarrow \mathrm{THEN}$ ' formulas, with the caveat that 'the arrow in rewrite formulas covers a wide variety of relations that has never been systematically categorized in the archaeological discourse' (Gardin, 2002: 277).

Here, I propose a methodology, reinterpreting Gardin's approach and implementing an IBE-based argumentation chain, that constitutes a framework for recording the complete sequence of archaeological reasoning underpinning the interpretation of a specific case study.

The starting point consists of adopting schematization, intended as a third way between the mathematical models and natural language and as a sort of hybrid genre 'distinctive of the social science and the humanities' (Gardin, 2002: 282). This does not entail abandoning narration in natural language, but instead greatly benefits the self-assessment of coherence and clarity of argumentation through a constant relation with the more condensed form of schematization. This model is then reshaped, in order to implement an IBE-based argumentation chain, with the framework identified by Amaya (2009), while considerations by her and by Fogelin (2007) on the nature of the best explanation are adopted in the evaluation phase.

The proposed pipeline consists of four main stages: the collection of records from an existing archive; the formulation of hypotheses; the definition of competing accounts; and the selection of the best explanation among several plausible candidates (Figure 5).

In the first stage, specific records (set SR in Figure 5) informed by the relevant issue at stake are selected from an archive (set R in Figure 5) comprising photographic, textual, visual, and analytical elements. In my case study (Campanaro, in prep.), I tackle the question whether the atrium of the House of the Greek Epigrams (Regio $\mathrm{V}$, Insula 1, 18) in Pompeii was roofed over or not in the last stage of its life and propose an archaeological interpretation in the form of a 3D digital reconstruction. In this instance, elements from the existing documentation ( $\mathrm{R}$ in Figure 6) concerning the state of the house (recent and past excavation reports, photographic campaigns, reproductions from the nineteenth century, etc.) have been selected.

In a second stage, a series of hypotheses making sense of one or more pieces from the collection of records included in the first group is defined (set $\mathrm{H}$ in Figures 5 and 6). This category also includes interpretations found in past reports and theories (e.g. archaeological, anthropological, social, etc.), elements that enter Gardin's 


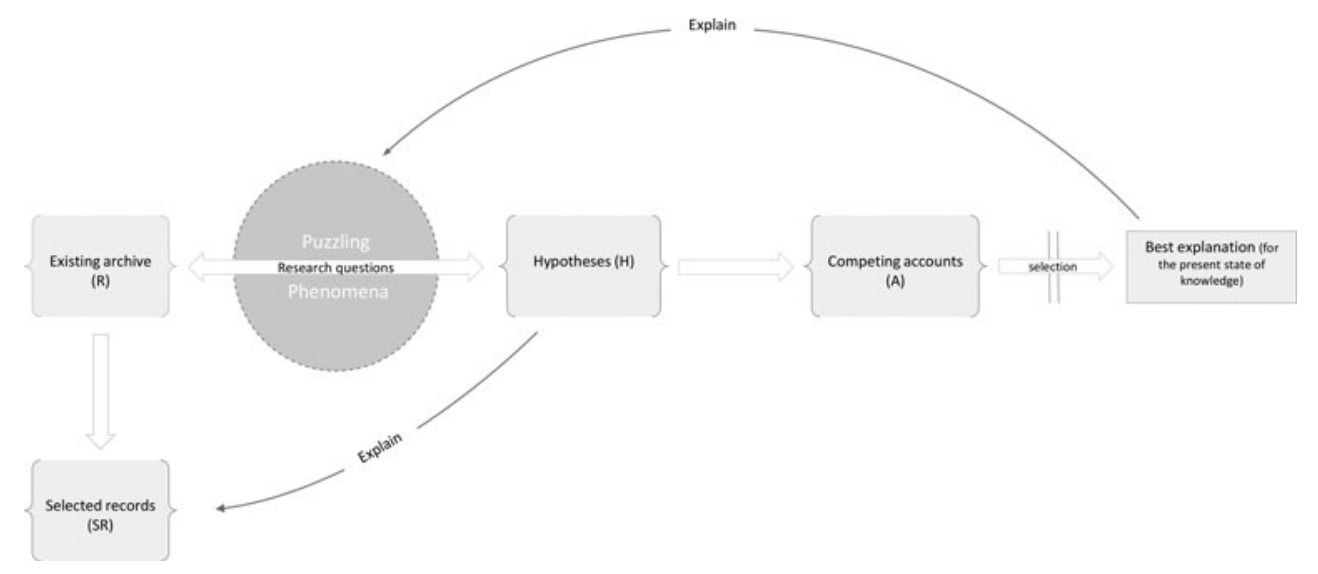

Figure 5. The IBE-based model for the recording of archaeological argumentation.

model at a database stage. The nature of the relation between one or more elements of the selected subset (SR) and the explaining hypothesis $(\mathrm{Hi})$ is not of the 'IF $\mathrm{p} \rightarrow$ THEN q' kind, as in Gardin, but of the 'Hi explains $\{\mathrm{SRi}\}$ ' type, where $\mathrm{Hi}$ is a hypothesis making sense of one or more pieces of information. In my Pompeii study, for example, instances of prestige (see H.2.1 in Figure 7) suggest that, at the House of the Greek Epigrams, an impluvium was added at a later stage, when the house received its second style decoration, along with a compluviate roof and a coffered ceiling.

The first two stages are informed by constant feedback between the record collection and the formulation of hypotheses in a sort of marshalling process (Amaya, 2009: 139) aimed at better organizing the information available. Importantly, within this iterative exchange between records and hypotheses, the formulation of the research questions plays a key role, in accordance with Amaya's (2009: 139) and Sintonen and Kiikeri's (2004: 227-33) ideas that a successful inquiry at this stage is primarily an exercise of interrogation. With respect to the Pompeii case study, a preliminary process of refinement made it possible to exclude roof styles such as Tetrastyle, Corinthian, testudinate, pent, or flat roofs, identifying the atrium tuscanicum (an inward sloping framework leaving an open space in the centre, the compluvium) as the most coherent solution among the hypotheses for a covered space.

At this point, a 'contrast set' of plausible competing accounts consisting of one or more subsets of the group of hypotheses (set $\mathrm{A}$ in Figures 5 and 6 ) is constructed and revised following coherence-making strategies of subtraction and addition, as explained earlier. Each account comprises one or more hypotheses, connecting interpretations and generating contrast sets among competing accounts. As the Pompeii example shows, in Figure 8, A1 and A2 represent two alternative 3D models pertaining to the accounts available: a roof structure of the atrium tuscanicum type or an open atrium with simple overhanging eaves.

A further process of refinement takes place when the 'virtues' discussed earlier (generality, empirical breadth, simplicity, etc.) are used to maximize the coherence and help select the best among the accounts based on the current state of knowledge. As this pertains to the Pompeii study, the accounts were assessed against the seven virtues of Quine and Ullian 


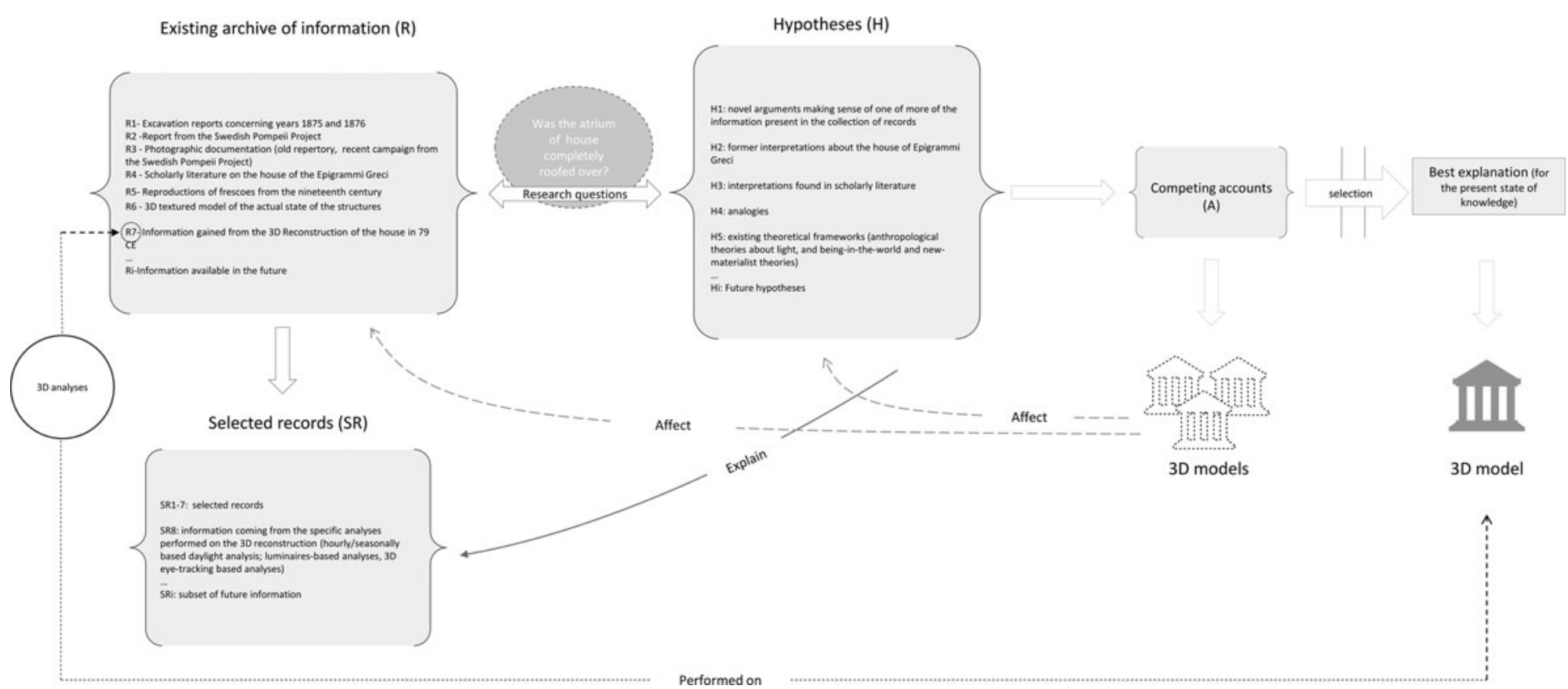

Figure 6. The IBE-pipeline applied to the case study of the House of the Greek Epigrams in Pompeii. 


\begin{tabular}{|c|c|c|}
\hline R.1.1/R.3.1 & Remains of walls to the east and west. & \\
\hline R.1.2/R.3.2 & Remains of shared walls to the north and south. & \\
\hline R.1.3/R.3.3 & Walled up window in the south-east corner of the atrium. & \\
\hline $\begin{array}{l}\text { R.1.4/R.2.1/R. } \\
\text { 3.4/R.6.1 }\end{array}$ & Wall paintings on the walls surrounding the atrium. & \\
\hline R.2.2 & Artifacts. & \\
\hline R.3.5 & $\begin{array}{l}\text { Inscriptions: Roman numerals on the north and south wall of } \\
\text { the atrium and an unreadable inscription on the north wall. }\end{array}$ & \\
\hline R.1.5/R.3.6 & Tufa impluvium. & \\
\hline R.1.6/R.3.7 & Thresholds. & \\
\hline R.3.8 & Cistern under the impluvium. & \\
\hline R.3.9 & Channel in the shaft of the cistern. & \\
\hline R.1.7/R.3.10 & Remains of pavement in lavapesta. & \\
\hline R.3.11 & Levels of the pavement. & \\
\hline R.1.8/R.3.12 & Window (North wall/room d). & \\
\hline R.3.13 & Irregular shape of the atrium. & \\
\hline
\end{tabular}

\begin{tabular}{|l|l|}
\hline H.1.1 & Appreciation from a distance. \\
\hline H.1.2 & Close-up appreciation. \\
\hline H.2.1 & Prestige. \\
\hline H.2.2 & Collection of water. \\
\hline H.2.3 & War damages and weathering. \\
\hline H.2.4 & Slope for the collection of water. \\
\hline H.3.1 & Partially covered space. \\
\hline H.3.2 & Covered space. \\
\hline H.3.3 & Servitudes. \\
\hline H.3.4 & Reception/Political patronage. \\
\hline H.3.5 & Domestic storage. \\
\hline H.3.6 & Water access. \\
\hline H.3.7 & Household industries. \\
\hline H.3.8 & Display. \\
\hline H.3.9 & Religious activity. \\
\hline H.3.10 & Circulation. \\
\hline
\end{tabular}

Figure 7. House of the Greek Epigrams in Pompeii case study. Left: the selected records (R); each record is associated with a coloured symbol. Right: the hypotheses $(H)$ explaining one or more of the selected records (represented with their respective symbol). 


\begin{tabular}{|l|l|l|}
\hline H.1.1 & Appreciation from a distance. \\
\hline H.1.2 & Close-up appreciation. \\
\hline H.2.1 & Prestige. \\
\hline H.2.2 & Collection of water. \\
\hline H.2.3 & War damages and weathering. \\
\hline H.2.4 & Slope for the collection of water. \\
\hline H.3.1 & Partially covered space. \\
\hline H.3.2 & Covered space. \\
\hline H.3.3 & Servitudes. \\
\hline H.3.4 & Reception/Political patronage. \\
\hline H.3.5 & Domestic storage. \\
\hline H.3.6 & Water access. \\
\hline H.3.7 & Household industries. \\
\hline H.3.8 & Display. \\
\hline H.3.9 & Religious activity. \\
\hline H.3.10 & Circulation. \\
\hline
\end{tabular}

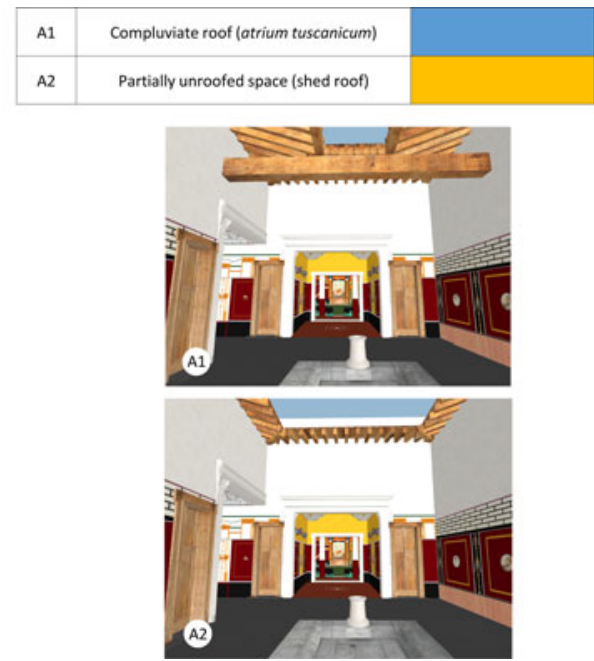

Figure 8. House of the Greek Epigrams in Pompeii case study. Left: the hypotheses (H). Right: the competing accounts $(A)$. Every account is associated with a colour (blue for compluviate roof and yellow for an open courtyard). In the hypotheses table (left), the relationship with the accounts is shown by cells coloured with the respective colour.

(1978), envisaging a roof structure of the atrium tuscanicum type as the solution best explaining the information available. The model has a certain permeability, giving specialists the possibility to introduce new elements (e.g. following new excavations or analysis, or if legacy documentation, such as old photographic records, is found) and retrace the entire chain of reasoning and possibly produce new findings resulting from a novel IBE-based process.

\section{Conclusions}

This study of IBE applied to archaeological reasoning, accompanied by a model for recording the argumentation process, reveals that this pattern of reasoning is highly relevant and answers a plea for the deployment of more solid argumentation. An IBE-based methodology is also capable of tackling issues of transparency and efficiency in the management of digital archaeological data.
Previous work shows that IBE has been a silent companion of archaeological argumentation for over a century; nevertheless, the lack of definition of specific models for the application of this pattern has led to limitations in its use. Consequently, examples of inference to the best explanation in the legal domain and of schematization of archaeological reasoning have been examined, with the aim of designing a novel IBE-based model for recording archaeological argumentation. Some findings from a case study in Pompeii illustrate how the IBE-based methodology presented here can be used in practice.

The proposed scheme has the potential to benefit the management of digital data in future, for example by including the schematization in the paradata that accompany the data to be stored. The approach described can easily be integrated within existing frameworks designed to improve transparency in the 3D reconstruction processes or efficiency in digital data management, providing us with an 
invaluable tool to enhance archaeological reasoning.

\section{Acknowledgements}

The author sincerely thanks the anonymous reviewers, the EJA technical editor Madeleine Hummler, and the editor Dr Catherine J. Frieman for their valuable comments and feedback. Special gratitude goes also to Prof. Henrik Gerding, Prof. AnneMarie Leander Touati and Dr Nicolò Dell'Unto for their constructive comments.

\section{REFERENCES}

Amaya, A. 2009. Inference to the Best Legal Explanation. In: H. Kaptein, H. Prakken \& B. Verheji, eds. Legal Evidence and Proof: Statistics, Stories, Logic. Aldershot: Ashgate, pp. 135-59. https://doi.org/10. 2139/ssrn.2044136

Amaya, A. 2015. The Tapestry of Reason: An Inquiry into the Nature of Coherence and its Role in Legal Argument. London: Hart Publishing.

Ben-Menahem, Y. 1990. The Inference to the Best Explanation. Erkenntnis, 33: 319-44. https://doi.org/10.1007/BF00717590

Binford, L. 1968. Archaeological Perspectives. In: S.R. Binford \& L.R. Binford, eds. New Perspectives in Archaeology. Chicago: Aldine Publishing, pp. 5-32.

Bruseker, G., Guillem, A. \& Carboni, N. 2015. Semantically Documenting Virtual Reconstruction: Building a Path to Knowledge Provenance. ISPRS, Annals of the Photogrammetry, Remote Sensing and Spatial Information Sciences, 2-5/W3: 3340. https://doi.org/10.5194/isprsannals-II5-W3-33-2015

Bunge, M. 2004. How Does It Work? The Search for Explanatory Mechanisms. Philosophy of the Social Sciences, 34: 182$210 . \quad$ https://doi.org/10.1177/ 0048393103262550

Campanaro, D.M. in prep. A Roof for the Atrium of the House of the Greek Epigrams in Pompeii? A Three-dimensional Critical Study.
Chapman, R. \& Wylie, A. 2016. Evidential Reasoning in Archaeology. London: Bloomsbury.

Crossland, Z. \& Bauer, A. 2017. Im/materialities. Semiotic Review, S.I., 4 [online] [accessed 28 October 2020]. Available at: <https://www.semioticreview.com/ojs/ index.php/sr/article/view/9>

Dallas, C. 2016. Jean-Claude Gardin on Archaeological Data, Representation, and Knowledge: Implications for Digital Archaeology. Journal of Archaeological Method and Theory, 23: 305-30. https:// doi.org/10.1007/s10816-015-9241-3

Demetrescu, E. 2015. Archaeological Stratigraphy as a Formal Language for Virtual Reconstruction: Theory and Practice. Journal of Archaeological Science, 57: 42-55. https://doi.org/10.1016/j.jas.2015.02.004

Demetrescu, E. \& Fanini, B. 2017. A WhiteBox Framework to Oversee Archaeological Virtual Reconstructions in Space and Time: Methods and Tools. Journal of Archaeological Science: Reports, 14: 50014. https://doi.org/10.1016/j.jasrep.2017.06. 034

Demetrescu, E., Ferdani, D., Dell'Unto, N., Touati, A.M.L. \& Lindgren, S. 2016. Reconstructing the Original Splendour of the House of Caecilius Iucundus: A Complete Methodology for Virtual Archaeology Aimed at Digital Exhibition. SCIRES-IT, Scientific Research and Information Technology, 6: 51-66. https:// doi.org/10.2423/i22394303v6n1p51

Douven, I. 2017. Abduction. In: E.N. Zalta, ed. The Stanford Encyclopedia of Philosophy (Summer 2017 edition) [online] [accessed 28 October 2020]. Available at: <https:// plato.stanford.edu/archives/sum2017/entries/ abduction/>

Dunnell, R.C. 1982. Science, Social Science, and Common Sense: The Agonizing Dilemma of Modern Archaeology. Journal of Anthropological Research, 38: 1-25.

Feldman, R. 2002. Epistemological Duties. In P.K. Moser ed. The Oxford Handbook of Epistemology. Oxford: Oxford University Press, pp. 362-83. https://doi.org/10. 1093/oxfordhb/9780195301700.003.0013

Feyerabend, P. 1975. Against Method. London: Verso.

Flannery, K.V. 1986. A Visit to the Master. In: K.V. Flannery, ed. Guila Naquitz: Archaic Foraging and Early Agriculture in 
Oaxaca, Mexico. Orlando (FL): Academic Press, pp. 511-19.

Fogelin, L. 2007. Inference to the Best Explanation: A Common and Effective Form of Archaeological Reasoning. American Antiquity, 72: 603-25.

Gardin, J.-C. 1980. Archaeological Constructs: An Aspect of Theoretical Archaeology. Cambridge: Cambridge University Press.

Gardin, J.-C. 2002. The Logicist Analysis of Explanatory Theories in Archaeology. In: R. Franck, ed. The Explanatory Power of Models. Dordrecht: Springer, pp. 267-84. https://doi. org/10.1007/978-1-4020-4676-6_13

Gardin, J.-C. 2004. Current Progress in Theoretical Archaeology. In: L.B. Višnjackij \& L.S. Klejn, eds. The Archaeologist: Detective and Thinker. St Petersburg: St Petersburg University Press, pp. 87-99.

Grize, J.-B. 1974. Logique mathématique, logique naturelle et modèles. Jahresbericht der Schweizerischen Geisteswissenschaftlichen Gesellschaft, 1974: 201-07.

Grize, J.-B. 2000. Les discours du savoir : pour un dialogue avec Jean-Claude Gardin. Revue Européenne des Sciences Sociales, 38: 131-37. https://doi.org/10.4000/ress.677

Haber, S. 1999. Anything Goes: Mexico's 'New' Cultural History. Hispanic American Historical Review, 79: 309-30. https://doi. org/10.1215/00182168-79.2.309

Halsall, G. 1997. Archaeology and Historiography. In: M. Bentley, ed. Companion to Historiography. London: Routledge, pp. 805-27.

Hanen, M. \& Kelley, J. 1989. Inference to the Best Explanation in Archaeology. In: V. Pinsky \& A. Wylie, eds. Critical Traditions in Contemporary Archaeology: Essays in the Philosophy, History, and SocioPolitics of Archaeology. Cambridge: Cambridge University Press, pp. 14-17.

Harman, G.H. 1965. The Inference to the Best Explanation. The Philosophical Review, 74: 88-95.

Harris, O.J. \& Cipolla, C. 2017. Archaeological Theory in the New Millennium: Introducing Current Perspectives. London: Routledge.

Hegmon, M. 2003. Setting Theoretical Egos Aside: Issues and Theory in North American Archaeology. American Antiquity, 68: 213-43.

Hempel, C.G. 1966. Pbilosophy of Natural Science. Boston (MA): MIT Press.
Hodder, I. 1984. Archaeology in 1984. Antiquity, 58: 25-32. https://doi.org/10. 1017/S0003598X00055940

Hodder, I. 1986. Reading the Past. Cambridge: Cambridge University Press. https://doi. org/10.1017/CBO9780511814211

Hodder, I. 1991. Interpretive Archaeology and its Role. American Antiquity, 56: 7-18.

Hodder, I. 1992. Theory and Practice in Archaeology. London: Routledge.

Hodder, I. 1999. The Archaeological Process: An Introduction. Oxford: Blackwell.

Iranzo, V. 2001. Bad Lots, Good Explanations. Critica, 33: 71-96.

Johnson, M. 2010. Archaeological Theory: An Introduction (2nd ed.) Oxford: Blackwell.

Kapitan, T. 1992. Peirce and the Autonomy of Abductive Reasoning. Erkenntnis, 37: 126. https://doi.org/10.1007/BF00220630

Kuhn, T.S. 1962. The Structure of Scientific Revolutions. Chicago (IL): University of Chicago Press.

Lakatos, I. 1970. Falsification and the Methodology of Scientific Research Programs. In: I. Lakatos \& A. Musgrave, eds. Criticism and the Growth of Knowledge. Cambridge (MA): MIT Press, pp. 365-95.

Lipton, P. 1993. Making a Difference. Philosophica, 51: 39-54.

Lipton, P. 2001. What Good is an Explanation? In: G. Hon \& S. Rakover, eds. Explanation. Dordrecht: Springer, pp. 43-59. https://doi. org/10.1007/978-94-015-9731-9_2

Lipton, P. 2004. Inference to the Best Explanation. London: Routledge.

London Charter 2009. The London Charter for the Computer-Based Visualisation of Cultural Heritage [online] [accessed 20 October 2020]. Available at: <http://www. londoncharter.org/>

Lucas, G. 2015. The Mobility of Theory. Current Swedish Archaeology, 23: 13-31.

Lucas, G. 2018. Writing the Past: Knowledge and Literary Production in Archaeology. New York: Routledge.

Magnani L. 2009. Abductive Cognition: The Epistemological and Eco-Cognitive Dimensions of Hypothetical Reasoning. Berlin, Heidelberg \& New York: Springer. https:// doi.org/10.1007/978-3-642-03631-6

Marlet, O., Zadora-Rio, E., Buard, P.-Y., Markhoff, B. \& Rodier, X. 2019. The Archaeological Excavation Report of Rigny: An Example of an Interoperable 
Logicist Publication. Heritage, 2: 761-73. https://doi.org/10.3390/heritage2010049

Mayr, E. 1982. The Growth of Biological Thought: Diversity, Evolution, and Inheritance. Cambridge (MA): Belknap Press.

McMullin, E. 1992. The Inference that Makes Science. Milwaukee (WI): Marquette University Press. https://doi.org/10.1111/j. 1467-9744.2012.01319.x

Merton, R.K. 1949. Social Theory and Social Structure. Glencoe (IL): Free Press.

Minnameier, G. 2010. The Logicality of Abduction, Deduction, and Induction. In: M. Bergman, S. Paavola, S.-V. Pietarinen \& H. Rydenfelt, eds. Ideas in Action: Proceedings of the Applying Peirce Conference. Helsinki: Nordic Pragmatism Network, pp. 239-51.

Niiniluoto, I. 1999. Defending Abduction. Philosophy of Science, 66: 436-51.

Okasha, S. 2000. Van Frassen's Critique of Inference to the Best Explanation. Studies in the History and Philosophy of Science, 31: 691-710. https://doi.org/10.1016/S00393681(00)00016-9

Okasha, S. 2002. Philosophy of Science: A Very Short Introduction. Oxford: Oxford University Press.

Paavola, S. 2005. Peircean Abduction: Instinct or Inference? Semiotica, 153: 131-54.

Peebles, C.S. 1992. Rooting Out Latent Behaviorism in Prehistory. In: J.-C. Gardin \& C.S. Peebles, eds. Representations in Archaeology. Bloomington (IN): Indiana University Press, pp. 357-84. https://doi. org/10.1525/aa.1993.95.3.02a00440

Peirce, C.S. 1931-1958. Collected Papers of Charles Sanders Peirce 1931-1958 edited by C. Hartshorne, P. Weiss \& A. Burks. Cambridge (MA): Harvard University Press.

Peirce, C.S. 1998. The Essential Peirce: Selected Philosophical Writings, vol. 2 1893-1913. Bloomington (IN): Indiana University Press.

Preucel, R.W. \& Bauer, A.A. 2001. Archaeological Pragmatics. Norwegian Archaeological Review, 34: 85-96.

Psillos, S. 1996. On van Frassen's Critique of Abductive Reasoning. The Philosophical Quarterly, 46: 31-47. https://doi.org/10. 2307/2956303

Quine, W.V. \& Ullian, J.S. 1978. The Web of Belief. New York: Random House.
Reichenbach, H. 1983. Erfabrung und Prognose. Braunschweig: Vieweg.

Reichertz, J. 2007. Abduction: The Logic of Discovery of Grounded Theory. In: A. Bryant \& K. Charmaz, eds. The SAGE Handbook of Grounded Theory. Los Angeles: SAGE, pp. 214-28. https://doi. org/10.4135/9781848607941

Salmon, M. 1982. Philosophy and Archaeology. New York: Academic Press. https://doi. org/10.1016/C2009-0-21943-X

Seville Principles 2017. The Seville Principles: International Principles of Virtual Archaeology ratified by ICOMOS, New Delhi, December 2017 [online] [accessed 28 October 2020]. Available at: <http:// sevilleprinciples.com/>

Shanks, M. \& Tilley, C. 1987. ReConstructing Archaeology. Cambridge: Cambridge University Press.

Sintonen, M. \& Kiikeri, M. 2004. Scientific Discovery. In: J. Wolénski, I. Niiniluoto \& M. Sintonen, eds. Handbook of Epistemology. Dordrecht: Kluwer Academic, pp. 205-53. https://doi.org/10.1007/978-1-4020-19869_6

Smith, M.E. 2015. How Can Archaeologists Make Better Arguments? The SAA Archaeological Record, 15: 18-23.

Thagard, P. 1978. The Best Explanation: Criteria for Theory Choice. Journal of Philosophy, 75: 76-92. https://doi.org/10. 2307/2025686

Thagard, P. 1989. Explanatory Coherence. Behavioral and Brain Sciences, 12: 435-502. https://doi.org/10.1017/S0140525X00057046

Thagard, P. 1992. Conceptual Revolutions. Princeton: Princeton University Press.

Trigger, B. 2006. A History of Archaeological Thought (2nd ed). Cambridge: Cambridge University Press. https://doi.org/10.1017/ CBO9780511813016

van Fraassen, B.C. 1989. Laws and Symmetry. Oxford: Clarendon Press.

Weintraub, R. 2013. Induction and Inference to the Best Explanation. Philosophical Studies, 166: 203-16. https://doi.org/10. 1093/0198248601.001.0001

Wylie, A. 2002. Thinking from Things: Essays in the Philosophy of Archaeology. Berkeley, Los Angeles \& London: University of California Press. 


\section{Biographical Notes}

Danilo Marco Campanaro is a doctoral student in Classical Archaeology and Ancient History at the University of Lund, Sweden. He is interested in the application of digital methods in archaeology. As a doctoral student, he is adopting digitally driven lighting simulation and analyses in support of the archaeological interpretation to investigate the enmeshments between spatial and social patterns in the Roman house.

Address: Department of Archaeology and Ancient History, Lund University, Helgonavägen 3, Lund, Sweden [email: danilo_marco.campanaro@klass.lu.se]. ORCID: 0000-0001-9962-6879.

\section{L'inférence à la meilleure explication (IME) en archéologie: un vieil outil et un nouveau modèle}

Les dernières décennies ont vu surgir un renouveau d'intérêt pour l'étude du raisonnement utilisé en archéologie, stimulé notamment par la surproduction d'interprétations et d'explications insuffisantes et peu fiables. En même temps, de récents appels à plus de transparence scientifique et à une gestion plus efficace des données numériques en archéologie ont souligné la nécessité d'exposer clairement les raisonnements suivis. Un nombre croissant de publications identifie l'inférence à la meilleure explication (IME) comme la meilleure façon d'interpréter les données archéologiques, bien que cette approche ait existé depuis plus d'un siècle. Cependant, l'étude de modèles basés sur l'IME pour enregistrer les raisonnements des archéologues reste un sujet peu abordé. L'auteur de cet article propose un nouveau modèle basé sur l'IME pour documenter les arguments avancés en archéologie. Translation by Madeleine Hummler

Mots-clés: inférence à la meilleure explication (IME), raisonnement en archéologie, archéologie numérique, restitution $3 \mathrm{D}$, trajectoire basée sur l'IME

\section{Inferenz zur besten Erklärung (IBE) in der Archäologie: altes Arbeitsgerät, neues Modell}

In den letzten Jahrzehnten hat sich ein erneutes Interesse für den Gedankengang in der Archäologie manifestiert, insbesondere als Reaktion auf die Überproduktion von schwachen und unzuverlässigen Interpretationen und Erklärungen. Gleichzeitig haben Aufrufe zu einer besseren wissenschaftlichen Transparenz und effizienteren Verwaltung von archäologischen Daten in digitaler Form auf die Notwendigkeit hingewiesen, das Verfahren zu verdeutlichen. Eine wachsende Anzahl von Veröffentlichungen zeigt, dass die Inferenz zur besten Erklärung (IBE) die geeignetste Methode für die Deutung von archäologischen Daten darstellt, wenn auch solch ein Vorgehen schon Jahrhundert-alt ist. Dennoch bleibt die Untersuchung von IBE-basierten Modellen, die den archäologischen Gedankengang belegen, relativ unerforscht. Der Autor schließt mit einem neuen IBE-basierten Vorgang, welcher die Überlegungen der Archäologen dokumentiert. Translation by Madeleine Hummler

Stichworte: Inferenz zur besten Erklärung (IBE), Gedankengang in der Archäologie, digitale Archäologie, 3D Rekonstruktion, IBE-basiertes Verfahren 